\title{
A IMPORTÂNCIA E OS BENEFÍCIOS DA ADMINISTRAÇÃO FINANCEIRA NAS MICROEMPRESAS E EMPRESAS DE PEQUENO PORTE
}

\author{
Lilian Aparecida Guiotoku, Irene Caires da Silva
}

Universidade do Oeste Paulista - UNOESTE, MBA em Finanças e Controladoria, Presidente Prudente, SP. E-mail: lilian.guiotoku@hotmail.com, irene@unoeste.com.br.

\section{RESUMO}

Em um setor promissor, com uma concorrência acirrada e a constante busca por otimização de resultados, estão as microempresas e empresas de pequeno porte, que para se manterem competitivas no mercado precisam tomar decisões corretas. Estatísticas mostram que cerca de $20 \%$ das empresas desse setor encerram as atividades antes de completar o segundo ano de vida, o que pode ser explicado pela falta de controle financeiro. Em virtude disto, o presente estudo é importante por demonstrar ao empresário os aspectos positivos de se ter uma administração financeira eficiente, sendo o objetivo deste artigo evidenciar a importância da administração financeira e apontar os benefícios. $O$ estudo foi baseado em uma abordagem qualitativa, com dados coletados através de trabalhos já realizados, evidenciando as ideias relatadas por outros autores, afim de concluir que a gestão financeira reduz o risco de uma pequena empresa encerrar suas atividades por falta de equilíbrio e planejamento financeiro.

Palavra-chave: Microempresa. Empresa de pequeno porte. Recurso financeiro. Controle. Fluxo de caixa.

\section{THE IMPORTANCE AND BENEFITS OF FINANCIAL ADMINISTRATION IN MICROENTERPRISES AND SMALL BUSINESS COMPANIES}

\begin{abstract}
In a promising sector with a strong competition and constant search for optimization of results, are micro-enterprises and small companies, which to remain competitive in the market need to make the right decisions. Statistics show that about $20 \%$ of companies in this sector end their activities before completing the second year of life, which can be explained by the lack of financial control. Therefore, the present study is important because it shows the entrepreneur the positive aspects of having an efficient financial management, the purpose of this article being to highlight the importance of financial management and to point out the benefits. The study was based on a qualitative approach, with data collected through work already done, evidencing the ideals reported by other authors, in order to conclude that financial management reduces the risk of a small company closing its activities due to lack of balance and financial planning.
\end{abstract}

Keyword: Microenterprise. Small business. Financial resource. Control. Cash flow. 


\section{INTRODUÇÃO}

A recessão econômica que acometeu o Brasil nos últimos anos desacelerou o surgimento de novas empresas, no entanto, mesmo com os efeitos prejudiciais provocados pela atual conjuntura econômica o segmento das Microempresas e as Empresas de Pequeno Porte tem papel de destaque na economia brasileira, já que representa a maioria dos estabelecimentos comerciais existentes no país.

Entretanto, as micro e pequenas empresas encontram dificuldades em se consolidar e se manter no mercado, e encerram suas atividades antes mesmo de completar o segundo ano de existência.

A mortalidade deste segmento de empresas não é resultante de uma razão isolada, mas sim de um conjunto de determinantes que levam ao fracasso nos primeiros anos de atividade como a falta de controle financeiro nas pequenas empresas.

Levando em consideração a situação citada acima, os aspectos apresentados anteriormente e o lugar de destaque que as micro e pequenas empresas possuem na estrutura produtiva e no mercado de trabalho no país, faz-se necessário um estudo a fim de expor ao empresário a importância e, as melhorias trazidas por uma gestão eficiente dos recursos financeiros nas pequenas empresas, além dos benefícios gerados à sociedade e ao país com a permanência das pequenas empresas no ambiente de negócios, por manter postos de trabalhos ativos e contribuir com o crescimento econômico do país.

Por este motivo, o presente estudo tem como tema, a importância da administração financeira nas micro e pequenas empresas, e como objetivo principal evidenciar a importância de uma administração financeira eficiente nas microempresas e empresas de pequeno porte e apontar os benefícios gerados.

\section{METODOLOGIA}

O referido estudo tem como metodologia científica a investigação aplicada, isto é, gera conhecimento através da aplicação prática da ciência em problemas do cotidiano, por meio de uma abordagem qualitativa, que segundo Gonsalves $(2005$, p. 58) "[...] preocupa-se com a compreensão, com a interpretação do fenômeno, considerando o significado que os outros dão às suas práticas".

Assim, o presente estudo é útil porque busca encontrar soluções aos problemas enfrentados no dia-a-dia pelos pequenos empresários na administração financeira de suas micro e pequenas empresas, a partir da interpretação das informações relacionadas ao tema em estudo.

Como instrumento de coleta de dados foi empregada a pesquisa bibliográfica, sendo realizada através de materiais publicados anteriormente, como livros, artigos científicos, dissertações, relatos de pesquisas, disponíveis em meio eletrônico e no formato físico.

Quer dizer que o estudo em questão, "[...] é um apanhado geral sobre os principais trabalhos já realizados, revestidos de importância, por serem capazes de fornecer dados atuais e relevantes relacionados com o tema". (MARCONI e LAKATOS, 2010, p. 142)

\section{RESULTADOS}

O empreendedorismo cresce ano a ano no Brasil, sendo a maioria das ideias de novos negócios concretizadas em micro e pequenas empresas, que é um setor que está em expansão no país.

No Brasil há 6,4 milhões de estabelecimentos comercias, dos quais $99 \%$ são micro e pequenas empresas, correspondendo por cerca de $44 \%$ da remuneração paga aos 
empregados formais das empresas privadas, conforme divulgado em 2017, pelo Departamento Intersindical de Estatísticas e Estudos Socioeconômicos (DIEESE) em seu endereço eletrônico, na 8a edição do Anuário do Trabalho nos Pequenos Negócios 2015.

As micro e pequenas empresas possuem um importante papel socioeconômico na economia nacional, uma vez que fomentam o desenvolvimento econômico do país por serem responsáveis por uma fatia generosa do faturamento das empresas brasileiras, e a alta empregabilidade gerada pelas empesas deste setor.

No entanto, em alguns casos a vida útil destas micro e pequenas empresas se encerram precocemente. De acordo com, Sebrae (2016), o relatório de outubro de 2016 do estudo "Sobrevivência das Empresas no Brasil" realizado pelo Serviço Brasileiro de Apoio ás Micro e Pequenas Empresas (SEBRAE) cerca de 23\% das MPEs não sobrevivem aos dois primeiros anos de atividade e $58 \%$ fecham as portas antes de completar cinco anos de vida.

A mortalidades das micro e pequenas empresas depende das ações e decisões do empreendedor, que antes de iniciar um negócio deve tomar uma série de cuidados, como, identificar e conhecer o nicho de mercado que vai atuar e principalmente saber administrar os recursos humanos, materiais e financeiros da empresa. (CHIAVENATO, 2007)

Vale ressaltar, que a gestão dos recursos financeiros não se restringe apenas as grandes empresas, também deve ser realizada pelos proprietários de micro e pequenas empresas, pois proporciona condições que garante rentabilidade e liquidez aos pequenos negócios.

Porém, "a maioria dos pequenos e médios empresários costuma administrar custos e finanças de maneira intuitiva, por não terem formação nessas áreas. " (CHIAVENATO, 2007, p. 224)

Assim, uma das principais causas do fechamento precoce das micro e pequenas empresas é a má administração das finanças o que leva a uma tomada de decisão subjetiva que na maioria das vezes causa o fracasso empresarial.

É por isto que se torna importante uma gestão financeira eficiente, assim o pequeno empresário poderá controlar os recursos e analisar a situação financeira da empresa, afim de maximizar os ganhos através do crescimento constante do lucro e, por consequência se consolidar no mercado.

Segundo Marcousé, Surridge e Gillespie (2013, p. 15), "as finanças têm dois aspectos principais: elas podem prover os números que ajudam os gerentes a tomar melhores decisões e podem demonstrar o que está acontecendo e o que aconteceu."

A gestão financeira está relacionada não somente às situações do presente, mas também à saúde financeira passada e futura da empresa, porque todas as movimentações de recursos financeiros são registradas.

Sendo que, a partir destes registros o pequeno empresário poderá visualizar e quantificar as entradas e saídas que ocorreram no caixa de sua pequena empresa, além de fazer projeções dos valores que deverão ser ingressados e desembolsados futuramente.

"Dentro do ambiente empresarial, a administração financeira volta-se basicamente para as seguintes funções: planejamento financeiro, controle financeiro, administração de ativos e administração de passivos. " (NETO e LIMA, 2017, p. 17)

Isto é, a administração dos recursos financeiros é um conjunto de ferramentas e ações administrativas que envolve todas as atividades financeiras da empresa, que consiste em controlar o recurso financeiro desde a origem até a sua destinação.

As ferramentas da gestão financeira são as demonstrações contábeis, como o Balanço Patrimonial, a Demonstração do Resultado do Exercício, a Demonstração de Fluxo de Caixa, o 
controle de custo e fluxo de caixa, a conciliação bancária, auditoria interna, entre outras.

Dentre as ferramentas mencionadas anteriormente destaca-se o controle de fluxo de caixa, já que as microempresas e empresas de pequeno porte poderão, opcionalmente, adotar uma contabilidade simplificada para registrar e controlar suas operações, conforme é estabelecido no artigo 27 da Lei Complementar 123/2006, além de que este recurso da administração financeira pode ser utilizado pelo empresário mesmo que não possua em sua empresa um sistema gerencial informatizado.

No computador em um programa de editor de planilha ou até mesmo numa planilha feita a mão é possível que o pequeno empresário tenha total controle sob a movimentação financeira de seu negócio por meio das anotações de recebimento de vendas e juros que são as entradas no caixa e, dos pagamentos a fornecedores, empregados, impostos, isto é, tudo aquilo que sai do caixa da empresa.

Essa importância do fluxo de caixa é confirmada por Silva (2009, p. 110):

O fluxo de caixa é o principal instrumento da gestão financeira que planeja, controla e analisa as receitas, as despesas, os custos e os investimentos, considerando determinado período projetado. Pode-se também dizer que consiste numa representação gráfica (planilha) e cronológica de entradas (ingressos) e saídas (desembolsos) de recursos monetários, permitindo às empresas executar todas as suas programações financeiras e operacionais, projetadas para um certo período de tempo, que pode ser diário, semanal, quinzenal, mensal, anual ou qualquer outro referencial de tempo, dependendo da necessidade de cada empresa.

Morante e Jorge (2012, p. 30) acrescenta ainda que, "as empresas devem ter uma previsão do seu dia-a-dia, dos valores que provavelmente serão depositados nos bancos nos diversos dias e dos valores que, com certeza, deverão ser pagos naquelas datas".

O fluxo de caixa é uma das mais importantes ferramentas de gestão financeira que a empresa tem à disposição, desconhecer ou ignorar o controle do caixa ocasiona a perda do controle das finanças da empresa.

“Uma empresa não poderá sobreviver por muito tempo em situação de inadequação do fluxo de caixa. Ela poderá ter margens unitárias de comercialização elevadas, mas se não tiver um fluxo de caixa equilibrado pode inviabilizar o seu projeto ou negócio. " (TÓFOLI, 2012, p. 92)

Visto que, a partir da administração do fluxo de caixa, o gestor está a par do montante de disponibilidades imediatas e obrigações financeiras que a empresa possui, sendo utilizado como instrumento de tomada de decisões. Pois, este método de controle financeiro, que pode ser realizado por meio de planilhas de Excel, demonstra detalhadamente os valores que entram e saem do caixa da empresa, permitindo a previsão de quantias e prazos de recebimento e pagamento.

A empresa quando faz uso do fluxo de caixa consegue reduzir a necessidade de capital de giro, diminuir os custos financeiros e dispor de recursos para realizar investimentos e arcar com suas obrigações com terceiros. (TÓFOLI, 2012)

Inúmeros são os benefícios trazidos a pequena empresa através da utilização de um fluxo de caixa cabe ao pequeno empresário executa-lo com eficiência para que os benefícios apareçam a longo prazo e, de imediato organize suas finanças.

\section{DISCUSSÃO}

O cenário brasileiro para os pequenos negócios é promissor, por isto a pequena empresa deve ser pensada de forma estratégica, onde todas as suas movimentações 
financeiras devem ser registradas e gerenciadas para que possam servir de base no processo decisório.

O empresário de pequeno porte deve estar capacitado para gerir as finanças de seu empreendimento, sendo que, o caixa é a parte mais sensível de uma empresa, onde se deve ter um fluxo de caixa bem desenhado, levando em consideração a atividade empresarial praticada e seu porte.

Através de uma planilha de fluxo de caixa o pequeno empresário irá administrar e planejar as disponibilidades e passivos financeiros, ou seja, as entradas e saídas do caixa da pequena empresa serão controladas, o que tornará possível mensurar os valores a receber e os valores que deverão ser pagos, além do saldo em caixa apurado através do confronto dos ingressos e egressos de recursos financeiros ao longo do período que está sendo analisado.

Com isto, os benefícios gerados serão: decisões acertadas acerca de avaliar o melhor momento para se fazer um novo investimento ou, se há a necessidade de capital externo para desafogar o caixa; gerenciamento dos gastos; controle e planejamento financeiro; elaboração de estratégias de compra, avaliando a melhor forma de pagamento, dentre outros.

À vista disso, os gestores de um pequeno negócio devem ter em sua rotina o hábito de anotar todas as operações financeiras de sua pequena empresa em uma planilha de controle de fluxo de caixa, para que possa utiliza-la como suporte na tomada de decisões e na melhoria de seu desempenho financeiro, permitindo otimizar e alocar os recursos monetários conforme o necessário.

Desta forma, terá o controle de suas finanças permitindo que se mantenha competitiva no mercado que atua, minimizando o risco de encerrar suas atividades por falta de equilíbrio financeiro.

\section{CONCLUSÃO}

O presente artigo se propôs a estudar a importância da administração financeira nas microempresas e empresas de pequeno porte, a fim de apontar os benefícios gerados à pequena empresa através de uma gestão financeira eficiente.

Observou-se que as micro e pequenas empresas alavancam o crescimento econômico do Brasil, já que a sua participação na economia nacional vem crescendo acentuadamente ano a ano, pois as empresas deste setor contribuem na geração de riqueza e postos de trabalho.

Justamente por ser um setor em expansão, o pequeno empresário precisa ter controle financeiro e monitorar o fluxo de caixa em tempo integral para que não passe a engrossar as estatísticas de fechamento de empresas.

Uma vez que, o encerramento das atividades de um pequeno negócio na maioria das vezes é provocado pela má administração dos recursos financeiros. O pequeno empreendedor costuma tomar decisões financeiras com base no seu feeling o que gera decisões que comprometem a saúde financeira da pequena empresa, pois desconhece a atual situação das finanças, como é fundamentado neste artigo através das ideias disseminadas por autores como Chiavenato, Silva, Tófoli e outros.

Nesse sentido, a administração financeira em uma micro ou pequena empresa é de suma importância para que possa se manter e destacar no mercado que atua. Essa administração consiste em registrar todas as operações financeiras realizadas pela pequena empresa com a finalidade de se ter absoluto controle financeiro e, os relatórios elaborados a partir desse controle irão servir de base no processo decisório. 
Entre as ferramentas utilizadas para se fazer a gestão financeira, o controle de fluxo de caixa é a mais simples de ser utilizada em um pequeno negócio, sendo que não necessita de um software de gestão ou, que o pequeno empresário domine as técnicas de administração e análise financeira.

Basta que o pequeno empreendedor anote todas as entradas e saídas de dinheiro do caixa de sua empresa separadamente em uma planilha e, no final do dia apure o saldo do caixa através da confrontação das quantias que ingressaram e que foram retiradas do caixa.

Isso permitirá que o gestor de uma micro ou pequena empresa tenha conhecimento do montante de recurso financeiro que tem a disposição e se é suficiente para arcar com as dívidas que possui, além de permitir que se faça uma previsão dos valores que deverão ser pagos e dos que se tem a receber, estimar prazos de recebimento e pagamento, avaliar novos investimentos ou a necessidade de capital de terceiros, gerenciar os gastos, entre outros benefícios.

Diante dos resultados encontrados, conclui-se que, uma gestão financeira eficiente das microempresas e empresas de pequeno porte é essencial para que possa se consolidar e se manter competitiva no mercado que atua. Isto porque, a utilização de um controle de fluxo de caixa proporciona ao empresário total controle sob as finanças de sua pequena empresa, podendo assim tomar decisões de acordo com a real situação financeira da empresa, com o propósito de melhorar o seu desempenho financeiro, pois irá otimizar e alocar as disponibilidades financeiras conforme a necessidade, reduzindo o risco de encerrar as atividades por falta de equilíbrio nas finanças do pequeno negócio.

\section{REFERÊNCIAS}

CHIAVENATO, Idalberto. Empreendedorismo: dando asas ao espírito empreendedor. 2.ed. São Paulo: Saraiva, 2007.

DIEESE, Departamento Intersindical de Estatística e Estudos Socioeconômicos. Anuário do trabalho nos pequenos negócios: 2015. 8.ed. Disponível em: $<$ https://www.dieese.org.br/anuario/2017/anuarioDosTrabalhadoresPequenosNegocios.ht $\mathrm{ml}$. Acesso em: 06 jan. 2018.

GONSALVES, Elisa Pereira. Conversas sobre iniciação à pesquisa científica. 4. ed. Campinas: Alínea, 2005.

IAN, Marcousé; SURRIDGE, Malcolm; GILLESPIE, Andrew. Finanças. São Paulo: Saraiva, 2013.

MARCONI, Marina de Andrade; LAKATOS, Eva Maria. Fundamentos de metodologia científica. 7. ed. São Paulo: Atlas, 2010.

MORANTE, Antônio Salvador, JORGE, Fauzi Timaco. Administração financeira: decisões de curto prazo, decisões de longo prazo, indicadores de desempenho. São Paulo: Atlas, 2012.

NETO, Alexandre Assaf; LIMA, Fabiano Guasti. Fundamentos de administração financeira. 3.ed. São Paulo: Atlas, 2017.

SEBRAE, Serviço Brasileiro de Apoio às Micro e Pequenas Empresas. Sobrevivência das Empresas no Brasil. Disponível em: 
<http://www.sebrae.com.br/Sebrae/Portal\%20Sebrae/Anexos/sobrevivencia-das-empresasno-brasil-relatorio-2016.pdf>. Acesso em: 10 fev. 2018.

SILVA, Edson Cordeiro da. Introdução a administração financeira: uma visão econômica e financeira para a gestão de negócios das pequenas e médias empresas. Rio de Janeiro: LTC, 2009.

TÓFOLI, Irso. Administração financeira empresarial. 1.ed. São Paulo: Raízes gráfica e editora, 2012. 